\title{
A Critical Appraisal Of Consumer Health Literature In Tamil Print News Media In Sri Lanka
}

\author{
Sri Ranganathan $S^{1}$, Balasubramaniam $R^{2}$, Thayakaran $M^{3}$, Thiruvarangan $S^{4}$, Vahine $N^{5}$ \\ ${ }^{1}$ Department of Pharmacology, Faculty of Medicine, University of Colombo \\ ${ }^{2}$ Medical Research Institute, Ministry of Healthcare and Nutrition \\ ${ }^{3}$ Adolescent Dental clinic, Colombo 4, Ministry of Healthcare and Nutrition \\ ${ }^{4}$ Allied Health Science Unit, Faculty of Medicine, University of Colombo \\ ${ }^{5}$ Medical student, Faculty of Medicine, University of Colombo
}

\begin{abstract}
Objective: This study was designed to critically appraise the consumer health literature (CHL) appearing in Tamil print news media (lay press or newspapers) in Sri Lanka
\end{abstract}

Methods: This cross-sectional descriptive study critically appraised the CHL appeared in National and regional Tamil newspapers published in Sri Lanka during a period of three months. We conducted a pilot study for a period of one week to identify all the Tamil newspapers published in Sri Lanka and also to determine the variables that can be used to appraise the CHL. CHL was defined as materials giving information on health related matters. Health advertisements and information on cosmetics were excluded. Two investigators independently went through all the target newspapers to identify and separate the CHL. Subsequently, using a pre-tested checklist, two investigators independently appraised the CHL. In case of major disagreement between the two investigators, decision was made by consensus.

Results: There were 633 CHL in 600 newspapers: Common topics included non-communicable diseases $(25 \%)$, reproductive health $(13 \%)$ and food habits (12. 6\%). Topics related to National public health campaigns, official health promotion messages, communicable diseases, medicines, vaccines, tobacco and alcohol were very minimal. Names and designation of the author/source was available only in $37.6 \%$ : Specialists, doctors, medical academics and medical students have authored the majority (79\%). $591 \mathrm{CHL}$ had some form of pictures, but in $70 \%$, the pictures were assessed to be irrelevant to the subject matter. Two-thirds were on very socially valuable topics whereas content was appraised to be of poor scientific merit and unreliable in 54\%.

Conclusions: Tamil newspapers are under utilised in disseminating important health messages to public and there is an urgent need to nurture medical journalism in Sri Lanka.

Key words: Newspapers, Print news media, health literature, consumer, Tamil

\section{Introduction:}

Print news media (lay press) continue to play a key role in communicating health information to patients and public. Casual glance of Sri Lankan newspapers shows that significant amount of health literature is published in print news media despite the growth of electronic and social media. However, researchers have commented that the health information appearing in mass media is subjected to little or no evaluation of content or effectiveness (1-3) in contrast to health information published in scientific publications. Researchers allege that the health literature appearing in mass media are mostly non-evidence based, inform processes rather than outcomes, generic and do not take into account the personal context in which treatment decisions are made (4-7). Yet, mass media is considered as a good asset to communicate health messages to public despite its inherent deficiencies such as poor validity, sensational and speculative (8-10).

Public are not informed whether the consumer

Corresponding author: shalini, email: sshalini14hotmail.com, iD https://orcid.org/0000-0003-0184-104X, Submitted: $10^{\text {th }}$ June 2019, Accepted: 25th November 2019 
health literature (CHL) targeting them has undergone any formal evaluation for its content, effectiveness or conflicts-of-interests. Scientific community which is very concerned about the quality of health literature disseminated to fellow scientists has not displayed much interest on the quality of CHL appearing in mass media. It has been reported that journalists and physicians belong to two different cultures with very little in common and often misunderstand each other $(11,12)$.

In Sri Lanka, CHL is published in print news media in different forms such as advertisements, articles, interviews, news items, business announcements, regular columns and product information. To our best of knowledge, there are no published studies from Sri Lanka critically

appraising CHL appeared in any type of mass media. Studies from other countries mostly focussed on selected topics (e.g.; tobacco) or looked at electronic or social media with limited studies on CHL appeared in print news media. A longitudinal study (1980-2000) of the Science Times Section of the New York Times concluded that the literature appeared in the Science Times (not limited to health) provided useful information to readers (13).

In Sri Lanka, only a minority is fluent in Tamil language (14). Consequently, readers who could scrutinise the CHL appearing in Tamil language are limited. Authors have frequently noticed inaccurate content, translation errors, misleading information, subtle self or product promotion in the guise of articles or columns on health related topics and irrelevant information in the CHL appearing in the Tamil print news media. Public are not informed about how the newspaper decides to accept a CHL item from a writer and his or her credibility and conflicts of interests. Hence, the objective of this study was to describe the CHL appearing in Tamil print news media in Sri Lanka and critically appraise their content.

\section{Methods:}

This cross-sectional descriptive study analysed the CHL appeared in National and regional Tamil newspapers published in Sri Lanka during the period of three months from October to December 2015.
The first challenge was to identify all Tamil newspapers published in Sri Lanka. Prior to main data collection, we did a market survey in North, East, Western, Central and Uva provinces. Popular paper shops in the main town of these Provinces were contacted and list of Tamil newspapers sold in their shops was collected. Since considerable number of Tamil population live in these provinces, we assumed that a Tamil newspaper which has a circulation volume will be definitely sold in one or more of these Provinces. We collated the names of Tamil newspapers obtained from all these shops and prepared a single list. Magazines and newsletters were excluded. Subsequently, all the issues of these newspapers published during the study period were bought from two popular newspaper shops, one located in Jaffna and the other in Colombo. They were collected from these shops weekly or fortnightly.

Second challenge was defining, identifying and separating the CHL from these newspapers. A detailed literature review failed to identify a suitable definition for CHL. Hence, we defined CHL as "materials intended/aimed to provide/ improve health literacy of public". The World Health Organization defines health literacy as "the cognitive and social skills which determine the motivation and ability of individuals to gain access to understand and use information in ways which promote and maintain good health" (15). Using these two definitions, we operationalised the definition of CHL as "any materials giving information on health related matters which

include, but not limited to, medicines, borderline substances, health promotion, preventive methods, surgeries, devices, general health aspects, nutritional supplements, specific diseases, food advice, vaccines, child care, infant formula, and dairy products". About two weeks before the main data collection, we bought one week (pilot period) issues of all the selected newspapers, studied them in detail and identified the major categories under which $\mathrm{CHL}$ is published. We decided to exclude advertisements and cosmetics. Subsequently, two investigators independently read the entire content of all the newspapers under the study and identified the CHL using the definition. Items identified as 
CHL by both investigators were separated from the newspapers and assigned a serial number.

Third challenge was selecting, describing and classifying the variables and critically appraising the content. Following variables namely type, topic, source/author, suitability of author, suitability of accompanying picture/s, appropriateness of Tamil phrases, social value of topic and scientific merit of the content were selected by going through about 50 issues published during the pilot period. Of the different types of CHL, it was difficult to differentiate articles from essays. When the content was objective, written in an order, did not contain quotations from unknown authors or experts and carried descriptive titles, they were to be classified as articles. CHL which did not conform to the above requirements were to be classified as essays. Topics which attract lay people (e.g.; fertility, physical appearance, child care, etc) were to be considered as socially valuable. Content which lacked either accuracy of reliability was to be considered as of poor scientific merit.

Fourth challenge was extraction of the required data from CHL. We developed an electronic check-list in Microsoft Excel programme to extract the relevant data from the CHL as checklists are useful tool for independent and objective appraisal of documents. This electronic checklist was pre-tested during the pilot period and subjected to few amendments. The investigators independently reviewed it for clarity, feasibility, user-friendliness, appropriateness and relevance. We decided on electronic format of checklist as we found it easy, convenient, saved paper and allowed quick transfer of data among investigators.

Using this electronic checklist, two investigators independently extracted the required data from the selected CHL to determine the variables given above. Accuracy and reliability were subjectively appraised by the investigators using multiple methods such as cross-checking with published literature on the topic, contacting experts, checking the sources quoted, common knowledge, looking for errors, completeness of information and presence of conflict -of - interests. In case of major disagreement between the two investigators, decision was made by consensus.

The study was exempted from ethics review by the ethics review committee of Faculty of Medicine, University of Colombo (EC-15-090). Though we analysed publicly available literature, no identification details are disclosed.

\section{Results}

During the market survey, we identified a total of 12 different Tamil newspapers published in Sri Lanka: 5 weekly, 5 daily and 2 weekdays only. This amounted to 600 newspapers during the 12 week study period (Table 1). We identified 633 CHL appearing in these 600 newspapers with a mean of 1.05 / paper and range of 0-15. Some newspapers had regular health section weekly, some carried regular columns by Medical Specialists and few carried CHL written by students of regional medical faculty. In the daily papers, CHL was limited to one particular day of a week with no CHL in the rest of the days.

\section{Table 1: Details of Newspapers.}

\begin{tabular}{|l|l|l|l|}
\hline $\begin{array}{c}\text { Frequen- } \\
\text { cy }\end{array}$ & $\begin{array}{c}\text { Number of } \\
\text { papers in the } \\
\text { respective } \\
\text { category }\end{array}$ & $\begin{array}{c}\text { Number/ } \\
\text { week }\end{array}$ & $\begin{array}{c}\text { Num- } \\
\text { ber/12 } \\
\text { weeks }\end{array}$ \\
\hline Daily & 5 & $(5 \times 7)=35$ & 420 \\
\hline $\begin{array}{l}\text { Weekdays } \\
\text { only }\end{array}$ & 2 & $(2 \times 5)=10$ & 120 \\
\hline $\begin{array}{l}\text { Weekly } \\
\text { (mostly } \\
\text { Sundays) }\end{array}$ & 5 & $(5 \times 1)=05$ & 60 \\
\hline Total & $\mathbf{1 2}$ & $\mathbf{5 0}$ & $\mathbf{6 0 0}$ \\
\hline
\end{tabular}

Almost all the daily newspapers had some form of CHL in their Sunday edition. Interestingly, nonSri Lankan doctors (mostly from South India) dominated as authors of CHL in Colombo based popular newspapers. Determining the type was difficult and subjective since there were frequent overlaps with no clear-cut margin between the different types. We agreed on the type based on consensus between the two reviewers. Details are given in Table 2. 
Table 2: Types of consumer health literature (CHL) appeared in the 600 newspapers

\begin{tabular}{|l|l|l|}
\hline Types & Number & Percentage \\
\hline Essay & 339 & 53.6 \\
\hline Article & 213 & 33.6 \\
\hline Interview & 21 & 3.3 \\
\hline News item & 41 & 6.5 \\
\hline Press meeting & 4 & 0.6 \\
\hline $\begin{array}{l}\text { Questions and } \\
\text { answers }\end{array}$ & 10 & 1.6 \\
\hline Research findings & 05 & 0.8 \\
\hline Total & $\mathbf{6 3 3}$ & $\mathbf{1 0 0}$ \\
\hline
\end{tabular}

These 633 CHL covered a wide array of topics (Table 3). Topics related to reproductive health accounted for $13.7 \%$ followed by food with therapeutic claims and healthy food (12.6), general topics (12.3) and individual diseases (10.6\%). Information on National public health campaigns, official health education messages, information about medicines, anti-bacterial medicines, vaccines and communicable diseases were poorly represented. Information on bad effects of alcohol was limited to 3 and smoking to $1 \mathrm{CHL}$.

Table 3: Topics of consumer health literature (CHL) appeared in the 600 newspapers

\begin{tabular}{|l|l|l|}
\hline Topic & No & \% \\
\hline Reproductive Health 1 & 87 & 13.7 \\
\hline Food & 80 & 12.6 \\
\hline General 2 & 78 & 12.3 \\
\hline Individual diseases 3 & 67 & 10.6 \\
\hline Self care & 59 & 9.3 \\
\hline Others 4 & 42 & 6.6 \\
\hline Child care & 41 & 6.5 \\
\hline $\begin{array}{l}\text { Heart diseases, hypertension, } \\
\text { obesity }\end{array}$ & 36 & 5.7 \\
\hline Mental Health & 31 & 4.9 \\
\hline Diabetes Mellitus & 29 & 4.6 \\
\hline $\begin{array}{l}\text { Complementary Alternative } \\
\text { Medicines 5 }\end{array}$ & 23 & 3.6 \\
\hline Cancer & 23 & 3.6 \\
\hline $\begin{array}{l}\text { News about innovations in } \\
\text { health related matters }\end{array}$ & 15 & 2.4 \\
\hline Human Immunodeficiency virus & 12 & 1.9 \\
\hline Eye & 10 & 1.6 \\
\hline Total & $\mathbf{6 3 3}$ & $\mathbf{1 0 0}$ \\
\hline
\end{tabular}

Specialist doctors having regular column and doctors (mainly from South India) writing about assisted reproduction services accounted for majority of topics in RPH. Consumer health literature on non-communicable diseases (NCD) when grouped together was very much higher $(\mathrm{N}=159,25 \%)$ than $\mathrm{CHL}$ on reproductive health $(\mathrm{N}=87,13.7 \%)$ with major NCDs (diabetes, cancers, heart disease, obesity, hypertension, mental health disorders) accounting for $18.7 \%$ $(\mathrm{N}=119)$ followed by renal disorders $(\mathrm{N}=14$, $2.2 \%)$, gastric ulcers $(\mathrm{N}=6,0.94 \%)$ and others $(\mathrm{N}=20,3.1 \%)$.

Source or author of the information was not indicated in $325 \mathrm{CHL}$ (51.3\%). They were just published as piece of information, some claiming as "from the web"; rest was mainly from individual authors $(244,38.5 \%)$ and research findings $(36,5.7 \%)$. Of the $308 \mathrm{CHL}$ which had indicated the source, name of the source was not disclosed in about $10.7 \%(\mathrm{~N}=33)$. Of the $275 \mathrm{CHL}$ which had disclosed the names, designation of the source was available only in 238 accounting for about $37.6 \%$ of the total $\mathrm{CHL}$ studied. Specialists, doctors, lecturers in medical subjects and medical students have authored the majority of CHL (79\%) followed by allied health professionals $(6 \%)$ and practitioners of complementary and alternative medicines $(5 \%)$. Information from government, non-government organisations and professional bodies working on health related matters was minimal.

Based on the given designation, authors of $91 \%$ $(218 / 238)$ of the CHL were assessed to be suitable to write on the given subject matter to consumers. One or more picture supplemented the writeup in 93\% (591/633) of CHL. However, 411 $(69.5 \%)$ of them were assessed to beirrelevant to the subject matter in the CHL including the 149 CHLs which appeared with author's photo. The latter accounted for over $60 \%$ of CHL authored by doctors.

Title of the CHL was appropriate in 387 (61.1\%), unnecessarily glorifying the message in 53 (8.4\%), wrong in $41(6.5 \%)$ and obvious self/ product advertising in $13(2.1 \%)$. Tamil phrases were acceptable for consumers in about $78 \%$ of the CHL $(\mathrm{N}=494)$ with rest assessed to be partial or poor carrying English words, direct translation 
of English words and terms unfamiliar to Sri Lankan Tamil speaking population. The latter problems were more apparent in CHL which did not have an author or source and CHL penned by non-Sri Lankan doctors.

Of the 244 CHL authored by individuals (doctors, allied health professionals, practitioners of CAM, non-specific, etc, almost half $(49 \%, N=119$ was contributed by South Indian doctors giving photos, qualification, designation and contact details.

Authors assessed that two-thirds of the CHL $(66 \%)$ were on highly socially valuable topics such as childlessness, skin care, diet, minor symptoms in children and pregnancy. On the other hand, content lacked scientific merit and appraised to be unreliable in $54 \%$ of CHL. These were mainly due to lack of evidence, bold statements, personal practice, self-advertisements and inaccurate claims.

\section{Discussion}

Though almost all newspapers had been publishing CHL with some having separate page and a designated reporter, there were many lapses. Unlike other news items, CHL is expected to make a change in the health behavior of readers. Hence, readers should be informed about the source or author of CHL. In the case of individual authors, this information should include details of designation and/or affiliations as just names mean nothing. This will help the readers to judge the authenticity of the information. However, only about one-third of the reviewed CHL had the necessary information about the source/authors.

Serious mismatch noted between the content and accompanying pictures in many CHL including the ones authored by reliable authors. There is a possibility that the authors may not have provided or approved the picture and reporters could have downloaded them from internet to attract the readers. However, irrelevant pictures may put off the readers from trusting the CHL. It is quite understandable that about two-third were reporting on socially valuable topics since the target is general public. However, reliability and accuracy of many CHL was questionable: They were either not supported by evidence or used by authors to self-advertise their services.
It is regrettable to note that the governmental organisations, professional bodies and nongovernmental organisations working on health related matters have not utilised this media to reach the public. No media releases by these organisations targeting public were seen in the Tamil newspapers during the study period. We are unable to comment whether this omission is limited only to Tamil newspapers or common to all newspapers published in Sri Lanka.

Medicines play a major role in prevention and treatment of diseases. Health interventions like mass administration of medicines for chemoprevention (e.g.; helminthiasis), micronutrient supplementation programmes (e.g.; iron, folic acid to young children), introduction of new vaccines beyond childhood (e.g.; human Papilloma virus vaccine) definitely require public knowledge and cooperation for success and sustainability. We feel that the newspapers still hold the power of reaching the people. Hence, organisations responsible for these health initiatives should make use of this media to get the correct message across to public.

Currently, large proportions of people are on some form of long-term medicines. Providing information about these medicines on individual basis at the time of prescribing by doctors or at the time of dispensing by pharmacists has major obstacles including lack of time and space. This leads to medicine illiteracy (lack of knowledge about the medicines taken by them) which in turn reduces the effectiveness of such medicines. Professional associations, Faculties of Medicines, Ministry of Health or individual doctors could use this platform to provide genuine, balanced, unbiased information about medicines to public. However, there was hardly any CHL on medicines in the $633 \mathrm{CHL}$ we analysed. Though, we pride ourselves on many landmark studies, findings from such studies are hardly communicated to public despite the fact impact of such findings are more relevant to local people than the international peers.

It was surprising to see that the bad effects of tobacco and alcohol did not feature prominently in the 633 CHL. Similarly, there was hardly any CHL on bad effects of beetle chewing which is a common practice among Tamil speaking tea 
plantation workers. There had been good attempts as well. One regional medical faculty students had published series of CHL in a regional

newspaper on NCDs. Similarly, few Sri Lankan medical specialists had been writing regularly on important topics. A regular question and answer section where a doctor answers question from readers is a good form of CHL. Alternatively, a journalist can collect answers for readers' questions from relevant experts and publish them regularly. A good quality CHL like this without any conflicts of interests would increase the popularity and sale of the newspaper. However, we did not see any such CHL in the three month study period.

Translation of medical jargon was also a limiting factor in the quality of the content. There is an urgent need for medical glossary in local languages which will ensure that both information provider and recipient use the same phrases. We are unable to comment whether the print media is over taken by electronic and social media in disseminating CHL. Similarly, we are not sure whether the underutilisation of newspapers in disseminating CHL is limited only to Tamil language due to limited number of interested professionals and journalists or common to both Sinhala and Tamil languages. Though considerable number of CHL had been authored by South Indian Tamil speaking doctors on various topics and services, we assessed the content of most of them was not very relevant to people living in Sri Lanka.

Our study has some limitations: There was no standard method in the literature and variables like social value and scientific merit were assessed subjectively and could not be quantified. This repots the situation in 2015. Despite these limitations, we have covered the entire lot of Tamil newspapers published in Sri Lanka and took meticulous precautions in data analysis. This is the first paper from Sri Lanka linking health information and news media. We hope researchers will further improve the methods and look at different aspects in this theme. Medical or health

journalism is an urgent need in Sri Lanka. Both healthcare and media organisations should come together and develop this discipline for the benefits of people of Sri Lanka.
This study was self-funded. None of the authors have any conflicts of interests

\section{References}

1. Bandiwadekar AS, Shanbhag N, Puranik MP. Oral health information in English newspapers: A content analysis study.J Indian Assoc Public Health Dent2014;12 :33-37 doi: 10.4103/2319-5932.138907

2. Gollust SE, Lantz PM. Communicating population health: print news media coverage of type 2 diabetes. SocSci Med2009; 69:10918. doi:10.1016/j.socscimed.2009.07.009

3. Meredith P, Emberton M, Wood C. New directions in information for patients. BMJ1995; 311:4-5. doi:10.1136/ bmj.311.6996.4

4. Cassels AK. The media-medicine mix: quality concerns in medical reporting. Open Medicine 2007; 1:e52-4.

5. Cook DM, Boyd EA, Grossmann C, Bero LA. Reporting science and conflicts of interest in the lay press. PLoS One 2007; 2:e1266.doi: 10.1371/journal.pone.0001266

6. Charnock D, Shepperd S, Needham G, Gann R. DISCERN: an instrument for judging the quality of written consumer health information on treatment choices. J Epidemiol Community Health1999; 53:10511. doi:10.1136/jech.53.2.105

7. Oxman AD, Guyatt GH, Cook DJ, Jaeschke R, Heddle N, Keller J. An index of scientific quality for health reports in the lay press.J ClinEpidemiol1993; 46:987-1001.

8. Grilli R, Ramsay C, Minozzi S. Mass media interventions: effects on health services utilisation. Cochrane database of systematic reviews 2002. doi:10.1002/14651858. CD000389

9. Kristiansen CM, Harding CM. Mobilization of health behavior by the press in Britain. Journalism Quarterly1984; 61:364-98.https:// doi.org/10.1177/107769908406100218

10. Hovsepyan O, Zare_Farashbandi F, Askari G, Hassanzadeh A. A survey on scientific authenticity of health information in Iranian 
popular magazines: A case study. J Educ Health Promot2018;7: 27 doi: 10.4103/jehp. jehp_85_17

11. Peters HP. The interaction of journalists and scientific experts: co-operation and conflict between two professional cultures. Media, Culture \& Society 1995; 17:31-48.https://doi. org/10.1177/016344395017001003

12. Nelkin D. An uneasy relationship: the tensions between medicine and the media. Lancet 1996; 347:1600-3. doi: 10.1016/ S0140-6736(96)91081-8

13. Clark F, Illman DL. A longitudinal study of the New York Times Science Times section. Science Communication 2006; 27:496-513. https://doi.org/10.1177/1075547006288010

14. Department of Census and Statistics, Sri Lanka. Census of Population and Housing: Final report; 2012
15. Nutbeam D. Health promotion glossary. Health promotion international 1998; 13:34964.

1. Frequent topics included menstruation, normal pregnancy, disorders in pregnancy, sub fertility, male fertility, gynaecological disorders, assisted reproduction, etc

2. Included non-specific titles (e.g.: Bones), topics without reference to any diseases (e.g.; advantages of sunlight, etc)

3. Remaining diseases which were not categorized separately

4. Included topics with frequency less than 10 namely dental, dengue, alcohol, joints, elders, environment and medicines

5. Mainly herbs, plants, etc - all with some form of therapeutic claims 